\title{
JUURNAL_RU
}

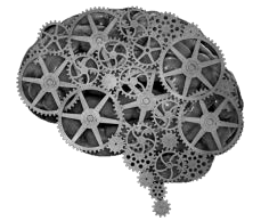

COMPANY GROUP "INTELLEKT"

\author{
Нестеренко О.А. \\ Ростовский государственный экономический университет (РИНХ) \\ Ростов, Россия
}

doi: 10.18411/lj2016-3-91

\section{Мультибрендинг, комаркетинг и кросс-промо: синергия программ лояльности фэшн - ритейла и торговых центров}

Разработка и реализация маркетинговых стратегий развития операторов фэшн - ритейла в значительной степени определяется не только конкуренцией в ритейл - кластере, но и теми изменениями, которые несет с собой изменение рынка торговых центров, их реконцепция и формирование нового позиционирования.

Стратегии развития фэшн - ритейла должны учитывать возможности, которые им даст совместная маркетинговая работа с девелоперами/управляющими компаниями ТЦ. Основной результат в части увеличения продажи повышения эффективности работы ТЦ и ритейла в них даст именно объединение программ лояльности.

Совместный маркетинг и совместные программы лояльности, бонусные системы, специальные платежные системы и услуги ТЦ для покупателя доставка, упаковка товара и комплексные предложения, а также кобрендинг все эти экономичные решения будут в кризис больше востребованы, нежели технологические инновации, требующие вложения денег» [4, с.44].

Мы наблюдаем кардинальные изменения в работе операторов рынка: частично галерея и якоря теперь меняются местами; маркетинг ТЦ и ритейла становится более интегрированным. Мы увидим новое позиционирование 
ритейла в ТЦ и растущую зависимость результатов его работы от синергии программ лояльности, эффективности позиционирования ТЦ.

То есть, в новом формате работы практика разрозненно рекламы у ТЦ и ритейла должна стать историей. Реклама ТЦ должна носить более целеориентированный характер: вместо рекламы отдельного магазина должна идти реклама ассортимента и привлекательности товарной группы.

При этом, такая интеграция будет дифференцированной и отличаться для различных ритейлеров. Часть из них, которая не понимает рынка и работает в рамках стандартных методов, будет более плотно взаимодействовать с командой маркетинга ТЦ. Крупные бренды, которые автономно генерируют трафик, могут выстраивать самостоятельные программы лояльности, продумывать их, и уже в готовом виде «вкладывать» в маркетинг ТЦ.

Основным и первоначальным условием для достижения синергии является ментальный слом арендаторов, которые по привычке разграничивают свой маркетинг и маркетинг ТЦ, особенно тогда, когда за маркетинг ТЦ приходится платить. «Арендодатели в России разделяют собственные маркетинговые мероприятия и меры продвижения арендатора. Хотя синергетический эффект от согласованных совместных акций был бы более выгоден как собственнику, так и ритейлеру. Мало кто принимает в расчет, что, продвигая собственные товар, услуги, товарный знак, арендатор косвенно увеличивает и посещаемость торгового центра».

Крупные сетевые игроки: «О’Кей», Madia Markt и т. д. - часто не платят маркетинговые сборы не только ввиду «якорности», но и потому что тоже предпочитают самостоятельную организацию продвижений» [3, с.44-45].

При этом, не только с точки зрения маркетинга, но и с экономической позиции оплата маркетинга ТЦ будет более эффективной, поскольку мотивация рекламных целей собственника ТЦ пересекается с мотивацией ритейлера. Комплексная реклама ТЦ дает эффект сразу всем участникам, генерируя поток покупателей для всех. 
На наш взгляд, ТЦ должны усиливать эффект синергии, отрабатывая различные форматы взаимодействия и объединения программ лояльности, обеспечивающего эффективность консолидированного бюджета ТЦ.

«Они имеют ограничения по конструктиву, конфигурации помещений, системам кондиционирования, к тому же имеют определенные проблемы с точки зрения концепции и позиционирования - далеко не всегда очевидно, что эта часть многофункционального комплекса является торговым центром. Bсе многофункциональные объекты, работающие сейчас, страдают, недополучая трафик и оборот» $[2$, с. 25$]$.

Данная проблема сегодня может сниматься за счет правильного развития развлекательного компонента, реконцепции ТЦ, изменения расположения арендаторов и навигации.

Как было установлено нами в ходе исследования, региональные ТЦ и ТЦ мегаполисов будут иметь различное позиционирование, набор брендов, масштаб развлекательной составляющей и уровень специализации. Заметим, что при этом маркетинг этих ТЦ будет решать неодинаковые задачи: в крупных ТЦ качественный и разнообразный шопинг должен быть дополнен инфраструктурой, позволяющей максимально комфортно провести здесь больше времени; в региональных ТЦ условия должны способствовать быстрому перемещению посетительских потоков, ротации посетителей.

При этом, маркетинг ТЦ и ритейла должен быть максимально сфокусирован на ядро целевой аудитории: эти посетители тратят больше, совершают целевые и импульсные покупки и, должны адсорбировать большую часть маркетингового бюджета. Наличие нежелательной аудитории (mall rats) требует жесткого таргетирования маркетинговых трат и активностей на эту часть аудитории.

Поскольку посещаемость в будние и выходные дни разнится, необходимо минимизировать этот разрыв через расширение инструментов привлечения новых целевых групп: какие товары интересны посетителям в будние дни, по 
каким специальным условиям их можно предложить. Для стимулирования продаж в эти периоды могут организовываться различные cross-promotion c арендаторами и/или ТЦ, что позволит дополнительно стимулировать продажи.

Заметим, что часть праздников проходят сами собой, и, нет необходимости стимулировать потребление в эти периоды чрез меры. При этом, существуют сезонные спады продаж. Их анализ по всем операторам позволит определить графики маркетинговой активности, наложение которых позволит выявить ременной перехлест, в течение которого следует запускать кросспроекты, направленные на привлечение целевого трафика.

Объединение программ лояльности должно базироваться на предшествующем ему глубоком маркетинговом анализе ТЦ, его специфических характеристик, определении целевой аудитории, ее структуризации с целью выработки инструментов адресного точечного воздействия.

При анализе покупательских потоков может формироваться сложная модель анализа, включающая оценку и учет таких параметров как [3, с.40-47]:

- продолжительность посещения ТЦ;

- число возвратов;

- комбинация посещаемых магазинов;

- частота посещения магазинов;

- направления и интенсивность движения потоков посетителей по ТЦ.

Оценивая потенциал использования геомаркетинга и маркетингового анализа ТЦ важно учитывать тот факт, что уровень взаимодействия ТЦ и ритейла в процессе повышения привлекательности ТЦ должен быть еще глубже. Синергии программ лояльности должно предшествовать более глубокое погружение арендодателя в проблемы арендаторов, оценка финансовых и рыночных рисков ритейлеров, анализ их проблем, что обеспечит общую синергию развития. Сокращение маржи ритейла должно прямоточно результироваться в стоимости аренды, что позволит им сократить затраты и 
увеличить маржу или лаг для конкурентного снижения цен для стимулирования продаж.

В конце 2014 г. - первой половине 2015 г. на рынке сложилась сложная ситуация, когда покупатели сравнивали цены за рубежом с ценами в российских ТЦ: последние даже при условии распродаж были завышены.

После завершения циклической коррекции рынка синергия ТЦ и арендаторов будет реально эффективной. Все это указывает на то, что стратегия роста ритейла в значительной степени будет определяться эффективностью работы ТЦ и взаимодействием с управляющими компаниями.

Снижение стоимости аренды, оптимизация маркетинговых расходов и повышение эффективности совместного стимулирования сбыта в перспективе будет определять границы оптимальной трансформации стратегий развития одежных сетей. В 2015-2016 гг. товарная матрица, например российских брендов в среднем сегменте будет изменяться в результате повышения доли bбрендов. При таком расширении и соответственно сужении модельного ряда внутри бренда сохранение общей матрицы может быть обеспечено за счет расширения сбытовой сети, что возможно при условии, если ТЦ проникнуться ситуацией, и, пойдут на компромиссное снижение стоимости аренды.

Данный вывод является еще одним подтверждением того, что кооперация ТЦ и ритейла должна быть более тесной. Соединение программ лояльности, маркетинга с точки зрения стимулирования сбыта должно быть дополнено оптимальными - компромиссными условиями контрактации, так как стоимость аренды определяет затратоемкость расширения сбыта и будет влиять на структуризацию ритейла и маркетинговые возможности его роста.

Новые условия контрактации через затраты в значительной степени также предопределяют возможности и ценового, и неценового позиционирования ритейлеров.

Данный тренд начинает носить стратегический характер, на что указывает, например, глубина снижения арендных ставок в локальных ТЦ, достигающая в 
конце 2014 г. - начале 2015 г. - 30-50\%. Даже такая коррекция валютной стоимости аренды не покрывает глубину падения рубля, но, тем не менее, является индикатором того, что ритейл и девелоперы начинают работать сообща. Коммерческие интересы отступают на второй план перед общим пониманием кризиса и изменения условий конкуренции на рынке, которые требуют максимального стратегического сближения арендатора и ТЦ.

Снижение стоимости аренды не является характерным для всех ТЦ. Например. В так называемых знаковых ТЦ, которые расположены в городах миллионниках, грамотно выстроены, имеют большой трафик и удобную транспортную развязку, девелоперы занимают более жесткую позицию по отношению к ритейлу. Использовав все возможности компенсировать высокую аренду высоким трафиком при относительно высокой маржинальности продаж, ритейл вынужден рассматривать локации в других ТЦ. Ранее, они не рассматривались им в принципе с точки зрения цены. Такого рода сложности испытывают транснациональные бренды, которые имеют все возможности перейти в новые ТЦ и самостоятельно генерировать в них свой покупательский трафик.

То есть, в 2015-2016 гг. характерным трендом будет являться изменение локации крупных транснациональных брендов, которые в определенной степени скорректируют прежние стратегии экспансивного роста.

«Многие сетевые бренды несколько лет назад открывали магазины десятками, сотнями в год, только чтобы увеличить свое присутствие на рынке. Это были такие гонки - кто больше, многие из магазинов в итоге так и не стали рентабельными. Теперь же арендаторам часто проще закрыть магазин, даже учитывая все штрафы, чем терпеть убытки» [1, с.20].

C нашей точки зрения, антикризисная трансформация стратегий роста операторов фэшн - ритейла будет достаточно дифференцированной. Для массового и среднего сегментов она будет опираться на расширение возможностей экспансивного роста за счет работы с ассортиментом, в 
премиумном сегменте же будут приняты на вооружение менее экспансивные стратегии развития. Если кризис и восстановление рынка затянется до 2018 г., покупатели будут пытаться разнообразить свой гардероб: мы увидим жесткую конкуренцию в среднем и нижнем сегментах рынка. Она приведет к повышению эффективности программ лояльности, усилению маркетинга и сужению простых форм стимулирования продаж, прежде всего, их дисконтирования.

В этих условиях репозиционирование ТЦ должно быть также ориентировано на инерционное посткризисное закрепление новых стратегий развития и маркетинга в различных сегментах рынка. То есть, это откроет возможности для определения специфики и границ позиционирования ТЦ, рорup-story которых будет завязано на определенный набор арендаторов, имеющих еще более схожую концепцию позиционирования.

Следует отметить, что в период кризиса ТЦ серьезно активизировали ротацию арендаторов в силу того, что их отдельные категории по-разному испытали «удар» кризиса. Тех, для которых он оказался критическим (верхний средний, премиум, нишевые операторы и малоизвестные мультибрендовые магазины) необходимо было спешно заместить на новых, более эффективных и устойчивых. На наш взгляд, вполне резонным будет предположить, что в условиях такой кризисной ротации ТЦ не имели возможности не столько сформировать более эффективную стратегию позиционирования ТЦ, сколько реально реализовать ее. Концепция позиционирования ТЦ могла быть отработана, но необходимость восполнения пустующих площадей не всегда позволяла выдерживать требуемый tenant mix, что на пике кризиса (конец 2014 г. - середина 2015 г.) несколько размывало позиционирование ТЦ.

Поэтому в 2016 г. по мере стабилизации рынка, концентрации спроса в сегментах, ТЦ смогут реализовать намеченные в кризис стратегии репозиционирования и формирования синергии программ лояльности с ритейлерами. 
Можно выделить два основных этапа кризисного изменения стратегий развития ТЦ: изменение в кризис и после кризиса. Смена этих стратегий будет проходить в виде фазовых переходов:

- от жесткой антикризисной ротации арендаторов: «собственники стараются сформировать наиболее оптимальный пул из сильных и устойчивых к экономическим трудностям арендаторов, который будет работать даже в условиях снижения доходов покупателей, а также поможет сохранить лояльность посетителей торгового центра и арендный доход» [1, с.22];

- к более продуманной концепции ТЦ и соответствующему «рор-up-story», объединению программ лояльности.

Заметим, что в 2015-2016 гг. девелоперы на фоне ужесточения конкуренции должны более твердо определиться со стратегиями позиционирования ТЦ, выбором конкурентной позиции и специализации на рынке, в рамках актуальной локации. Это позволяет нам предположить, что в этот период может наблюдаться определенный пересмотр - селекция арендаторов или формирование более четких представлений об их составе, сообразно оптимальной концепции позиционирования молла.

В разгар кризиса можно было наблюдать более хаотичный всплеск маркетинговых активностей, совместных акций с арендаторами, появление новых развлекательных форматов и т.д. Задач этой «пожарной» маркетинговой активности - поддержать трафик в условиях кризиса. Аналогичным образом, приоритет получили арендаторы, не столько органично вписывающиеся в концепцию позиционирования ТЦ, сколько обеспечивающие удержание трафика (якорные и мини-якорные арендаторы, эксклюзивные бренды, нетрадиционные для рынка концепции).

В 2016-2017 гг. по мере более детальной отработки и реализации концепций ТЦ этот состав может поменяться. Это позволяет сделать вывод о том, что наиболее интенсивным процесс ротации арендаторов будет в региональных ТЦ и ТЦ районного масштаба, особенно до конца 2015 г. В 2016 г. 
по мере укрепления рубля и восстановления доходов населения, рост продаж у ритейла приведет к стабилизации коммерческих условий аренды.



Рисунок 1 - Синергия программ лояльности операторов fashion - ритейла (арендаторов) и торговых центров

В данных условиях эффективным будет развитие различных cross promo альянсы, обеспечивающие увеличение покупательского потока посредством реализации комплексных программ, предлагающих покупателю не просто скидку, а целый набор разнообразных услуг, подарки и скидки.

В целом, резюмируя основные выводы, можно констатировать следующее. Современная кризисная трансформация рынка резко актуализировала необходимость синергии программ лояльности ТЦ и операторов фэшн ритейла, необходимость перехода к которой назрела уже давно. 
Тем не менее, как мы показали выше, кризис ограничил возможности резкой конвергенции программ лояльности ввиду ротации арендаторов, попыток ТЦ восполнить пустующие площади, постепенного перехода девелоперов к реконцепции объектов по мере понимания того, что рынок торговой недвижимости сильно изменился и требует большей специализации и более узкого позиционирования.

Основная причина неэффективности мультибрендовых программнечеткое позиционирование на целевую аудиторию, что приводит к его размытости и снижению маркетинговой эффективности. Такие комплексные программы лояльности имеют смещенный фокус и не находят необходимого отклика у потребителя. Кроме того, как было эмпирически доказано нами в ходе анализа, существующие программы лояльности достаточно схожи, что снижает возможности объединения операторов с одинаковой целевой аудиторией. Это означает скидки, стандартные системы накопления бонусных баллов и т.д.

Кроме того, существуют объективные ограничения для синергии программ лояльности (см. рис. 1):

- - неравномерность развития программ: разрыв в числе клиентов приводит к тому, что один ритейлер вытягивает другого;

- - сложность технологической интеграции программ лояльности;

- - дорогой софт;

- - расхождение акций и мероприятий каждого из арендаторов с установками и требованиями ТЦ;

- - различная глубина скидок и автономные программы лояльности конкретных брендов;

- - нежелание торговых марок раскрывать собственные базы данных, непонимание возможности управления ими в единой программе девелопера без риска утечки информации. 
Все это позволяет нам резюмировать, что дальнейшее наращивание девелоперами маркетинговой активности будет происходить в условиях неготовности отдельных операторов участвовать в совместных проектах, например ввиду наличия минимальной торговой наценки.

Проведенный анализ показал, что параллельная оценка развития ТЦ и фэшн - ритейла имеет под собой реальные эмпирические основания и позволила нам более обоснованно и детально показать:

- - каким образом будет происходить трансформация стратегий развития операторов фэшн - ритейла;

- - насколько их изменение определяется изменением конкуренции на рынке ТЦ, новыми тенденциями в реконцепции и репозиционировании моллов;

- - какие направления стратегического развития мы увидим на стыке уплотняющейся кооперации арендаторов и ТЦ;

- - каковы особенности синергии программ лояльности ТЦ и арендаторов.

С нашей точки зрения, и на уровне стратегического, и на уровне операционного маркетинга научно-практический анализ развития одежных компаний априори должен быть привязан к оценке изменений, происходящих на рынке ТЦ, и, торговой недвижимости в целом. Такая привязка формирует важный методический императив и должна быть должным образом отражена в современных маркетинговых исследованиях одежного ритейла в России.

То есть, современное развитие потребительского рынка в России, его одежного сегмента в частности, свидетельствует о том, что данный рынок еще не является насыщенным, что образует траекторию развития фэшн - ритейла в малонасыщенной низкоконкурентной среде. Это же самое происходит и на рынке торговых центров. Кризис 2014-2015 гг., равно как и кризис 2008-2009 гг. выступили своего рода точками бифуркации, по прохождении которых и ритейл и моллы сильно изменились. 
Выход ритейла и ТЦ на новый этап развития приведет к серьезным изменениям в программах лояльности, корректировка которых отчасти будет проводиться с целью получения дополнительного эффекта от их синергии с другими ритейлерами и ТЦ.

В 2016-2017 гг. fashion - сегмент торговой отрасли технологически и операционно придет в состояние реализации качественных мультибрендовых программ лояльности, под которые операторами будут использованы все имеющиеся возможности.

Все это приведет к радикальной трансформации программ лояльности. Они будут вложены в новые стратегии развития ритейлеров и девелоперов, которые должны в корне изменить свое отношение к программам лояльности.

\section{Литература:}

1. Арсенин Е. С толпою на выход // CRE Retail. - 2015. - №28. Июльавгуст.

2. В Вишнепольская Ю. А вокруг тишина // CRE Retail Marketing. - 2013. - №10(11). ноябрь.

3. Реуцкая Е. Черные дыры на золотом дне // CRE Retail Marketing. 2013. - №9(10). октябрь.

4. С миру по фишке // CRE Retail. - 2015. - №31. ноябрь. 